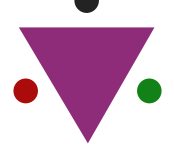

IJCRR

Section: Healthcare

Sci. Journal Impact

Factor: $6.1(2018)$

ICV: 90.90 (2018)

(c) (9) (3)

Copyright@IJCRR

\title{
A Retrospective Evaluation of Traumatic Dental Injuries in Children Visiting Dental Setup in Delhi- NCR
}

\author{
Juneja A $^{1}$, Sultan A $^{2}$, Siddiqui $\mathbf{M}^{3}$
}

\begin{abstract}
'Associate Professor, Department of Pediatric and Preventive Dentistry, Faculty of Dentistry, Jamia Millia lslamia, New Delhi, India; ${ }^{2}$ Professor, Department of Pediatric and Preventive Dentistry, Faculty of Dentistry, Jamia Millia Islamia, New Delhi, India; ${ }^{3 T u t o r}$, Department of Pediatric and Preventive Dentistry, Faculty of Dentistry, Jamia Millia lslamia, New Delhi, India.
\end{abstract}

\section{ABSTRACT}

Rationale: Dental trauma during childhood and adolescence is a health hazard as it is commonly associated with accidents, sports activities and violence.

Objectives: This study aimed to understand the characteristics and factors associated with anterior tooth trauma in the case reported in a dental college of Delhi-NCR during the 5 years (2011-2016).

Methods: A retrospective cross-sectional analysis of dental records of patients of the age group of patients of age 6-13 years with anterior tooth trauma, reported in 5 years, was done, and injury-related data for permanent dentition was collected. Statistical analysis was performed using the Chi-square test $(p<0.05)$.

Results: Ellis Type II (Enamel-dentin) fractures were the most common type (29\%), followed by Ellis Class VII (24\%). Permanent Maxillary central incisors were the most commonly affected teeth. Only $9 \%$ of patients reported within 4 hours of anterior tooth trauma. The prevalence rate was $55 \%$ in males and $45 \%$ in females with no statistically significant difference.

Conclusion: Traumatic dental injuries can adversely affect the physical as well as the psychological growth of children and adolescents. Health promotion and educational policies are needed to provide create awareness at ground level and to motivate patients for immediate intervention.

Key Words: Accidents, Health education, Permanent teeth, Retrospective, Tooth trauma, Traumatic dental injuries

\section{INTRODUCTION}

Dental trauma during childhood and adolescence is a health hazard as it is commonly associated with accidents, sports activities and violence. It affects the overall quality of life of an individual including the physical and psychological aspect. ${ }^{1}$ Some studies have reported body injuries as a major cause of mortality in people of the age group 12- 24 years. ${ }^{2,3}$ There is a wide variation in the prevalence of dental injuries throughout the world. While in some review studies it has a wide range of 6-59\%. ${ }^{2}$ Some authors report the prevalence to be approximately $15-30 \%$ in primary dentition and $16-40 \%$ in permanent teeth in children aged 6-12 years old. ${ }^{4}$ This can also be interpreted as approximately one-third of all children till the age of 12 experience dental trauma at least once during their life. In Asian countries, the prevalence of traumatic injuries to anterior teeth among adolescents ranges from $4 \%$ to $35 \% .5,6$
First 3 years of child is considered the age of greatest incidence of dental trauma to primary dentition, as this is the period during which motor skills develop. ${ }^{7}$ The common cause of injuries to permanent dentition is secondary to falls, accidents, sports activities and violence. Anterior tooth trauma cases may present in mild form as a subluxation or a severe form as crown fracture, root fracture, luxations, intrusion extrusion or avulsion. ${ }^{8}$ Late complications of traumatic dental injuries include pulpal necrosis, inflammatory root resorption, pulp canal obliteration secondary to continuous calcification of the pulp etc. Increased overjet and insufficient lip coverage are reported as significant predisposing factors. ${ }^{9}$ These cases of traumatic injuries could have an improved outcome if there is better public awareness regarding first-aid measures and the necessity to seek immediate treatment. Prevention of traumatic anterior tooth injuries by spreading public awareness is only

\section{Corresponding Author:}

Dr. Akanksha Juneja, Associate Professor, Department of Pediatric and Preventive Dentistry, Faculty of Dentistry, Jamia Millia Islamia, New Delhi, India; Ph: 9971404330; Email: ajuneja@jmi.ac.in.

ISSN: 2231-2196 (Print)

Received: 24.07 .2020
ISSN: $0975-5241$ (Online)

Revised: 13.09 .2020
Accepted: 19.10 .2020 
possible only if it is based on reliable, complete and comprehensive data of cases of traumatic dental injuries, which should include the type of tooth trauma, age, risk factors, prevalence, causes, present awareness of parents and reasons for the delay in seeking treatment.

The purpose of the current retrospective study was to analyze the recorded data related to the anterior tooth trauma of the patients seen in the clinic of Department of Pediatric and Preventive Dentistry, Faculty of Dentistry, during 2011-2016, and to assess the relationship if any, based on the gender, age, number of injured teeth, and type of traumatic anterior tooth injury and the post-trauma period after which patient reports for a first dental visit.

\section{MATERIAL AND METHODS}

The present cross-sectional retrospective study was carried out in the Department of Pediatric and Preventive Dentistry of a dental college in Delhi. The study was reviewed and approved by an Institutional Ethics Committee (Proposal 21/6/65/JMI/IEC/2016). The dental records of all patients in the age group of 6-13 years seen by the dental surgeon in the OPD of the department, from June 2011 to May 2016, were examined for the collection of data. Out of the entire database, male and female patients of the selected age group, with a history of anterior tooth trauma to permanent dentition were included. Cases with incomplete documentation or no dental trauma and children with special health care need having dental trauma were excluded. Data relating to gender (male to female ratio), age, number of injured teeth, tooth affected and type of trauma, the time elapsing between the injury and the presentation for treatment was collected. As dental injuries are mostly related to anterior teeth; hence data collection was limited to dental injuries to the four maxillary and the four mandibular permanent incisors. Records of all acute and non-acute dental visits that related to the treatment of traumatized permanent anterior incisors within the 5-year study period were reviewed.

Tooth fracture was assessed according to Ellis and Davey classification of fractures (1970). ${ }^{5,10}$ Data analysis included frequency and percentage distribution and cross-tabulation. Statistical analysis was performed using the Chi-square test $(\mathrm{p}<0.05)$.

\section{RESULTS}

After screening the entire data from June 2011 to May 2016, it was observed that a total of 183 children $(2.5 \%$ of the total patient number) presented with anterior tooth trauma involving permanent teeth, 272 teeth being affected. Of these $45 \%$ case were reported in females; while $55 \%$ were reported in males, which was not statistically significant (Table 1). Out of the total number of cases reported $61 \%$ cases were of single tooth trauma; while $39 \%$ of cases of multiple tooth trauma (Table 2, Figure 1). A comparison of age of occurrence of dental trauma showed that maximum of $26 \%$ of cases happened in the age group of 11-12 years, followed by $12-13(24 \%)$ and $10-11$ years (23\%) (Table 3 and Figure 2). Ellis type II was the most common type of traumatic dental injury seen (29\%); followed by Ellis Class VII (24\%) (Table 4 , Figure 3). Cases of avulsion were seen only during the age group of 7-8 years and 8-9 years (Table 5, Figure 4). In the age group of 8-9 years, Ellis Class VII was a most common type of dental trauma whereas in all the other groups Ellis class II was a most common type (Table 5, Figure 4). Only $9 \%$ of patients reported within 4 hours of dental injury, while $5 \%$ reported between 4 hours to 1 day. $10 \%$ of patients reported within 1 week; while maximum patients $(35 \%)$ reported between 1 to 6 months post dental trauma (Table 6 , Figure 5). Permanent Maxillary Central Incisor was the most commonly involved tooth in the cases reported (Table 7, Figure 6).

\section{DISCUSSION}

The present retrospective study was conducted in the Department of Pediatric and Preventive Dentistry, in a government college in Delhi, India. The OPD where this study was performed is located in a low socio-economic area and treats minor facial trauma including soft tissue lacerations with tooth involvement. The present study can, therefore, be considered to cover reliably the whole spectrum of minor tooth traumas among the low socioeconomic population in Delhi, India. Higher numbers of traumatic dental injuries i.e. $73 \%$ were recorded in 10-13 years age group. This study has highlighted that the occurrence of dental injuries increased according to age, which was maximum in the 10-13-year age group as reported in earlier studies. ${ }^{11-13}$

The male to female ratio for the current population was found to be $1.24: 1$ which was not found to be statistically significant. This ratio has been shown to vary with different regions. Patel et al. (2012) observed male to female ratio of 1.28:1 in children of the age group of 8-13 years in Vadodara city, Gujarat, ${ }^{14}$ while in Mumbai, Maharashtra, the ratio was found to be 1.6:1 in the age group of 13-14 years. ${ }^{15}$ Many past studies have concluded that males experienced traumatic dental injuries more frequently than females in the permanent dentition; with a ratio ranging from 1.3 to $2.5: 1$ respectively. ${ }^{2}$ This could be ascribed to the fact that males have been seen to have greater involvement in contact sports, violent behaviour etc. ${ }^{16,17}$ However, it is now being observed in recent studies that gender disparity is on a decline, ${ }^{16,18}$ as was evident in this study. This could be attributed to an increased involvement of females in sports indoor and outdoor 
as well as in violent activities.

Majority of epidemiological studies have suggested that anterior teeth are most commonly affected in permanent dentition and the majority of cases being of single tooth trauma. ${ }^{2,4,19}$ Gabris et al. (2001) in a retrospective study of 15 years concluded that $70 \%$ of the cases were of single tooth trauma with the most common injury type observed was an enamel-dentin crown fracture. ${ }^{13}$ In the present study also $61 \%$ of the cases were of single tooth trauma with Permanent Maxillary Central Incisor being most frequently affected tooth. The present study showed Type II (enamel and dentin fracture) as the most common type of fracture and accounted for $29 \%$ of the total fractures, followed by Type VII and Type III. Protrusive position and being inadequately covered by upper lip make maxillary central incisors more prone to anterior tooth trauma. ${ }^{20,21}$ Also, the maxillary arch is rigid whereas mandible is movable, making maxillary arch more prone to a certain type of tooth injury. ${ }^{22}$ Ellis and Davey Classification of fractures (1970) were preferred for this study as compared to other classifications, as it was reliable, easy to use and comprehend from the data available. ${ }^{10}$ The Ellis classification of fractures of anterior teeth has been used in many previous studies for recording traumatic dental injuries. ${ }^{23,24}$

In the present study, only $9 \%$ of patients reported within 4 hours of dental injury; while $35 \%$ reported within 1 week to 6-month post-trauma. The maximum percentage of patients $(41 \%)$ reported after a minimum of 6 months post-trauma. In majority cases, the patients visited the dental clinic only after the appearance of signs and symptoms of sensitivity, pain and swelling etc. The study also revealed that patients who had suffered trauma without symptoms or obvious complications did not consult dental clinics and were therefore seen at routine appointments. ${ }^{9}$ Delayed reporting for treatment could be attributed to the fact that maximum patients reported from low socioeconomic status; where awareness regarding seeking dental treatment post-trauma is low. Due to financial constraints also not, much importance is given to dental treatment, especially if no signs and symptoms are present.

However, this study had limitations. Since it was a retrospective study, the aetiology of the trauma, various treatment procedures and their success could not be assessed. A prospective longitudinal study can be useful to find the association of various types of anterior tooth trauma, the etiological and risk factors and treatment success.

\section{CONCLUSION}

Traumatic dental injuries can adversely affect the physical as well as the psychological growth of children and adolescents. Health promotion policies are needed to provide affordable treatment and at the same time create a safe environment around the school, home and society. Educational policies are needed to create awareness regarding the prevention of trauma as well as about the benefits of the immediate treatment and how that can minimize the sequelae of traumatic injuries.

\section{ACKNOWLEDGEMENT}

Authors acknowledge the immense help received from the scholars whose articles are cited and included in references to this manuscript. The authors are also grateful to authors/ editors/publishers of all those articles, journals and books from where the literature for this article has been reviewed and discussed.

\section{Conflict of interest: None}

\section{Financial support: None}

\section{REFERENCES}

1. Moura LB, Carvalho PA, Faria GD, Gonçalves LB, Post LK, Xavier CB. A 10-year retrospective study of dental trauma in permanent dentition. Revista Española de Cirugía Oral Maxilofacial 2018; 40(2): 65-70.

2. Lam R. Epidemiology and outcomes of traumatic dental injuries: a review of the literature. Aus Dental J 2016; 61(1): 4-20.

3. Australian Institute of Health and Welfare. Eldridge D. Injury among young Australians. AIHW bulletin no. 60. Cat. no. AUS 102. Canberra: AIHW, 2008.

4. Glendor U. Epidemiology of traumatic dental injuries: a 12-year review of the literature. Dent Traumatol 2008: 24:603-11.

5. Tasneem SA, Ravishankar LT, Sultan S, Tangade P, Telgi CR, Tirth A, et al. Prevalence of Traumatic Dental Injuries to Anterior Teeth of 12-Year-Old School Children in Kashmir, India. Arch Trauma Res 2016; 5(1): 1-8.

6. Gupta S, Kumar-Jindal S, Bansal M, Singla A. Prevalence of traumatic dental injuries and role of incisal overjet and inadequate lip coverage as risk factors among 4-15 years old government school children in Baddi-Barotiwala Area, Himachal Pradesh, India. Med Oral Patol Oral Cir Bucal. 2011; 16(7):e960-5.

7. Guideline on management of acute dental trauma. American Acad. Ped Dent., Reference Manual 2011; 32(6), 202-212.

8. Lexomboon D, Carlson C, Andersson R, von Bultzingslowen I, Mensah T. Incidence and causes of dental trauma in children living in the county of Värmland, Sweden. Dent Traumatol 2016; 32: 58-64.

9. Kahabuka FK, Plasschaert A, Van't Hof MA. Prevalence of teeth with untreated dental trauma among nursery and primary school Dar es Salaam, Tanzania. Dent Traumatol 2001; 17:109-113.

10. Young EP, Ellis RB, Lake BD, Patrick AD. Tay-Sachs disease and related disorders: Fractionation of brain N-acetyl-beta-hexosaminidase on DEAE-cellulose. FEBS Lett. 1970;9(1):1-4.

11. Rai S, Munshi AK. Traumatic injuries to the anterior teeth among south Kanara school children - a prevalence study. J Indian Soc Pedod Prev Dent. 1998; 16:44-8.

12. Govindarajan M, Reddy VN, Ramalingam K, Durai KS, Rao PA, Prabhu A. Prevalence of traumatic dental injuries to the anterior teeth among three to thirteen-year-old school children of Tamilnadu. Contemp Clin Dent 2012; 3(2):164-7. 
13. Gabris K, Tarjan I, Rozsa N. Dental trauma in children presenting for treatment at the Department of Dentistry for Children and Orthodontics, Budapest, 1985-1999. Dent Traumatol 2001; 17: 103-108.

14. Patel MC, Sujan SG. The Prevalence of Traumatic Dental Injuries to Permanent Anterior Teeth and Its Relation with Predisposing Risk Factors Among 8-13 Years School Children of Vadodara City: An Epidemiological Study. J Indian Soc Pedod Prev Dent 2012;30(2):151-7.

15. Hegde R, Agrawal G. Prevalence of Traumatic Dental Injuries to the Permanent Anterior Teeth among 9- to 14-year-old Schoolchildren of Navi Mumbai (Kharghar-Belapur Region), India. Int J Clin Pediatr Dent 2017;10(2):177-182.

16. Zaleckiene V, Peciuliene V, Brukiene V, Drukteinis S. Traumatic dental injuries: aetiology, prevalence and possible outcomes. Stomatologija 2014; 16:7-14.

17. Navabazam A, Farahani SS. Prevalence of traumatic injuries to maxillary permanent teeth in 9- to 14-year-old schoolchildren in Yazd, Iran. Dent Traumatol 2010; 26:154-157.

18. Trabert J, Bittencourt DD, Peres KG, Peres MA, de Lacerda JT, Maecenas W. Aetiology and rates of treatment of traumatic dental injuries among 12-year-old schoolchildren in a town in southern Brazil. Dent Traumatol 2006; 22:173-178.
19. Chopra A, Lakhanpal M, Rao N, Gupta N, Vashisth S. Traumatic dental injuries among 12-15-year-old-school children in Panchkula. Arch Trauma Res. 2014;3(1):e18127. DOI:10.5812/ atr. 18127

20. Baccetti T, Antonini A. Dentofacial characteristics associated with trauma to maxillary incisors in the mixed dentition. J Clin Pediatr Dent 1998; 22:281-4.

21. Hunter ML, Hunter B, Kingdon A, Addy M, Dummer PMH, Shaw WC. Traumatic injury to maxillary incisor teeth in a group of South Wales school children. Endod Dent Traumatol 1990; 6:260-264.

22. Jokic NI, Bakarcic N, Fugosic V, Majstorovic M, Skrinjaric I. Dental trauma in children and young adults visiting a University Dental Clinic. Dent Traumatol 2009; 25: 84-87.

23. Tangade PS. The prevalence of anterior teeth fracture and its relation to malocclusion in 12 and 15 -year-old schoolchildren Belgaum City, India. J Oral Health Commun Dent 2007; 1:7-11.

24. Kaur A, Mohindroo A, Thakur G, Ahlawat B. Anterior tooth trauma: A most neglected oral health aspect in adolescents. Ind J Oral Sci 2013;4(1):31.

Table 1: Gender wise distribution of trauma cases

\begin{tabular}{lcc} 
Gender & Total patients reported & Percentage of cases \\
Males & 101 & 55 \\
Females & 82 & 45 \\
\hline
\end{tabular}

Table 2: Distribution According To Gender and No Of Teeth Involved

\begin{tabular}{lccc} 
Cases of Trauma & & Male & Female \\
Cases of single tooth trauma & 112 & 62 & 50 \\
Cases of multiple tooth trauma & 72 & 39 & 32 \\
Total trauma cases & 183 & 101 & 82 \\
\hline
\end{tabular}

Table 3: Age-wise distribution of cases

\begin{tabular}{lcc} 
Age Group & Number of cases & Percentage \\
$7-8$ years & 6 & $3 \%$ \\
$8-9$ years & 21 & $11 \%$ \\
9-10 years & 23 & $13 \%$ \\
$10-11$ years & 42 & $23 \%$ \\
$11-12$ years & 48 & $26 \%$ \\
$12-13$ years & 43 & $24 \%$ \\
\hline
\end{tabular}

Table 4: Distribution between Gender and Dental Injuries

\begin{tabular}{ccccc} 
Ellis Anterior Tooth Trauma Type & No of teeth involved & \multicolumn{2}{c}{ Gender } \\
I & 21 & Percentage & Male & Female \\
II & 80 & $8 \%$ & 14 & 7 \\
III & 61 & $29 \%$ & 44 & 36 \\
IV & 34 & $22 \%$ & 36 & 25 \\
V & 10 & $13 \%$ & 14 & 20 \\
VII & 66 & $4 \%$ & 8 & 2 \\
\hline
\end{tabular}


Table 5: Distribution between Age and Dental Injuries

\begin{tabular}{lcccccc} 
Ellis Type & \multicolumn{5}{c}{ Age } \\
& $\mathbf{7 - 8}$ years & $\mathbf{8 - 9}$ years & $\mathbf{9 - 1 0}$ years & $\mathbf{1 0 - 1 1}$ years & $\mathbf{1 1 - 1 2}$ years & 12-13 years \\
I & 1 & 2 & 4 & 6 & 6 & 2 \\
II & & 4 & 12 & 26 & 20 & 18 \\
III & 1 & 7 & 7 & 17 & 15 & 14 \\
IV & 6 & 4 & 4 & 3 & 11 & 13 \\
V & 4 & 15 & 9 & 6 & 17 & 15 \\
VII & 12 & 35 & 36 & 58 & 69 & 62 \\
Total & & & & & & \\
\hline
\end{tabular}

Table 6: Distribution according to Time of Reporting

\begin{tabular}{lc} 
Reporting time since trauma & No of cases \\
Within 4 hours & 16 \\
Within 4-24 hours & 10 \\
1 day to 1 week & 19 \\
1 week to 6 month & 64 \\
6 - 12 month & 27 \\
$1-2$ years & 38 \\
$2-3$ years & 6 \\
3-4 years & 3 \\
\hline
\end{tabular}

Table 7: Distribution of affected tooth according to TDI type

\begin{tabular}{lccccccc} 
Tooth involved & No of cases & Class I & Class II & Class III & Class IV & Class V & Class VII \\
Right Maxillary Central Incisor & 126 & 11 & 35 & 28 & 17 & 5 & 30 \\
Right Maxillary Lateral Incisor & 6 & 1 & 2 & & 1 & 2 & 2 \\
Left Maxillary Central Incisor & 121 & 9 & 34 & 29 & 14 & 4 & 31 \\
Left Maxillary Lateral Incisor & 5 & & 1 & & & 1 & 3 \\
Left Mandibular Central Incisor & 8 & & 4 & 2 & 2 & & \\
Right Mandibular Central Incisor & 5 & & 3 & 2 & & & \\
Right Mandibular Lateral Incisor & 1 & & 1 & & & & \\
Total & & 21 & 80 & 61 & 34 & 10 & 66 \\
\hline
\end{tabular}

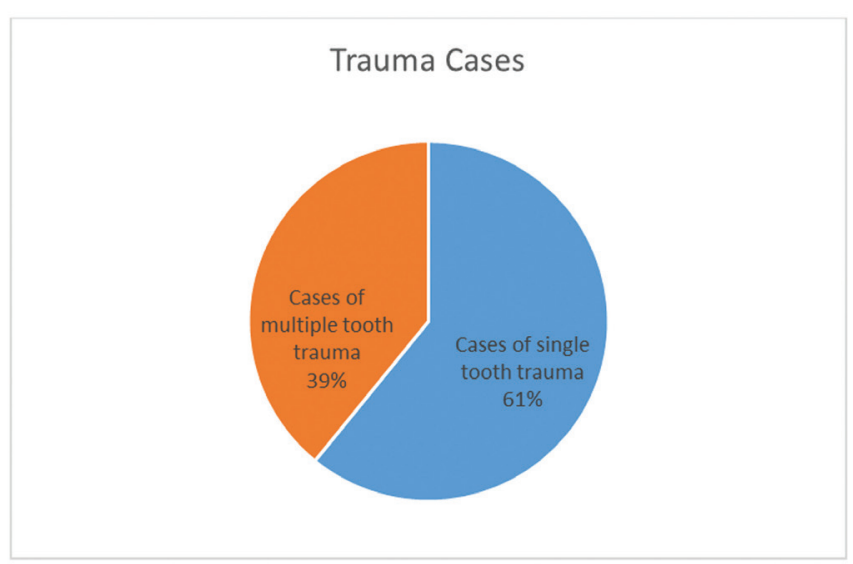

Figure 1: Distribution of single and multiple tooth trauma.

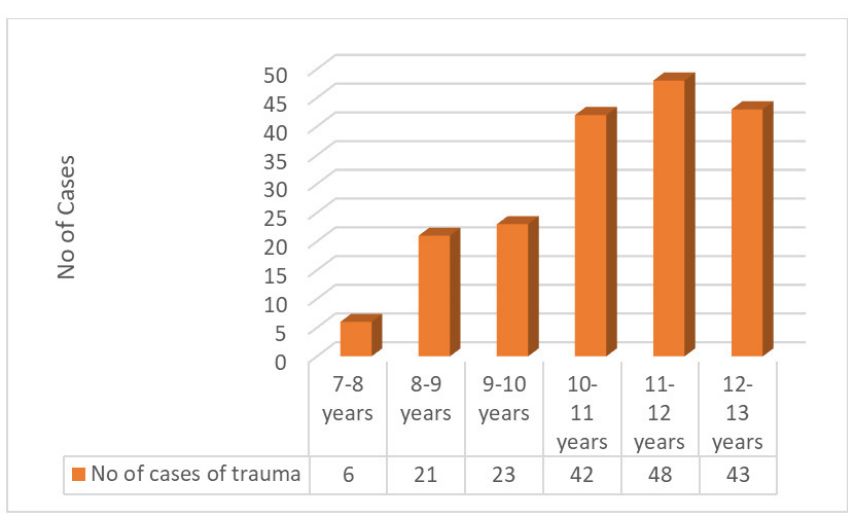

Figure 2: Age-wise distribution of cases. 


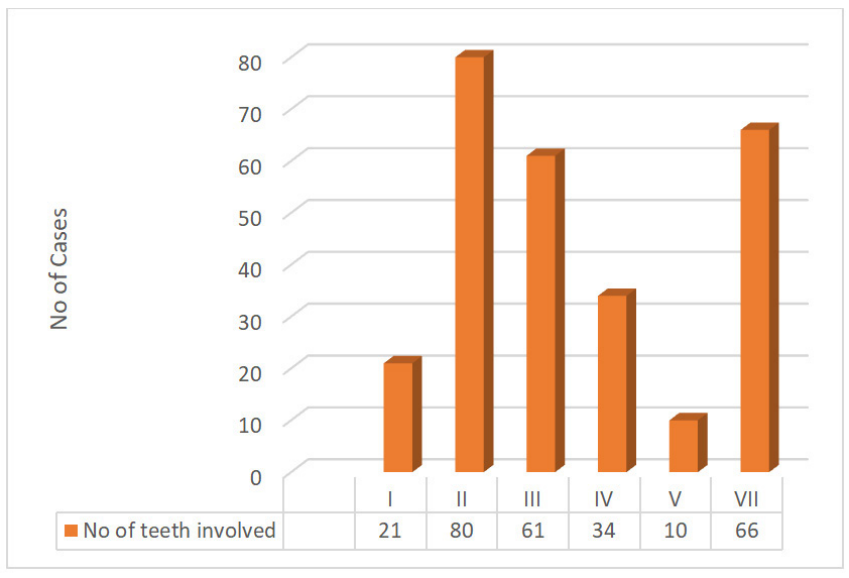

Figure 3: Distribution according to Ellis classification of Trauma.

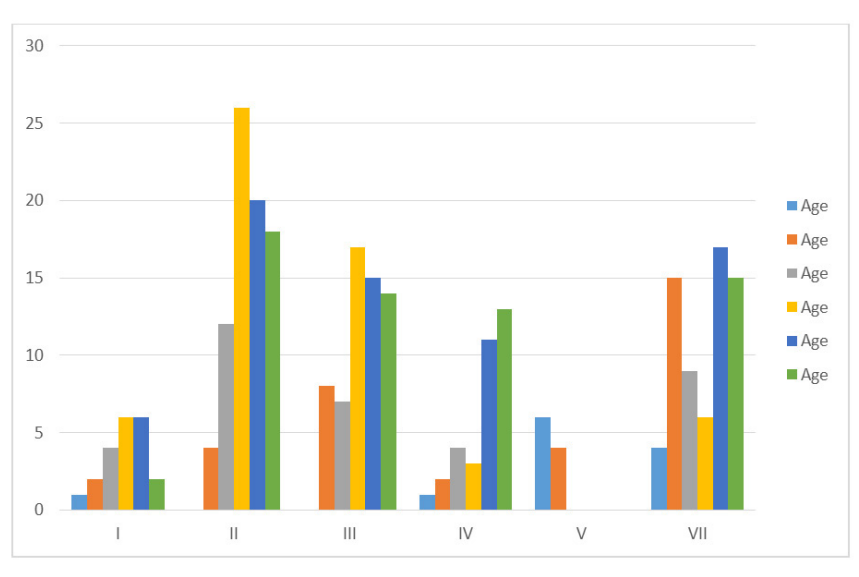

Figure 4: Age wise distribution of type of trauma.

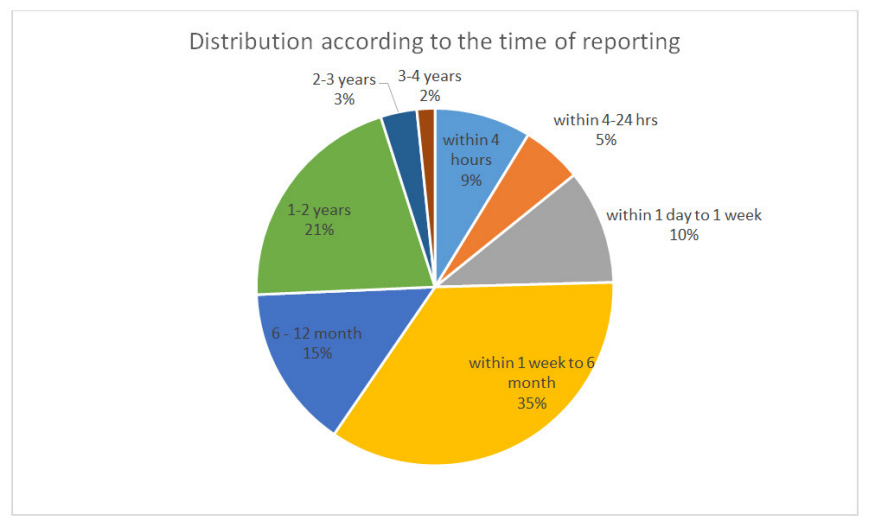

Figure 5: Distribution according to the time of Reporting post trauma.

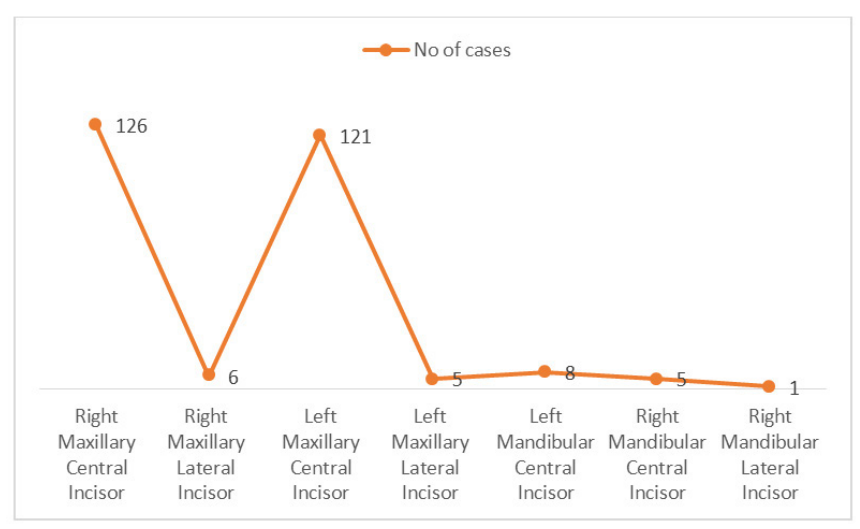

Figure 6: Distribution according to tooth involvement. 